\title{
WERKMONSTERS AS KEURINGSTOETSE ${ }^{*}$
}

\author{
J.B. WOLFAART
}

DEPARTEMENT BEDRYFSIELKUNDE

UNIVERSITEIT VAN SUID-AFRIKA

\begin{abstract}
A work sample is a replica of the work on which applicants demonstrate their ability to successfully perform the work sample and therefore the job it represents. The greatest advantage of a work sample is the similarity with the job of which it is a replica, which prevents unfair discrimination among applicants. The greatest disadvantage of work samples is that for many jobs it will be impossible to standardise this type of test. A literature study has indicated that work samples are reliable and valid selection tests, especially for jobs which require psycho-motor abilities.
\end{abstract}

Die keuring van personeel vir spesifieke beroepe met behulp van sielkundige toetse is standaard praktyk en suksesvol in talle organisasies. Hoewel suksesvol, maar minder algemeen in gebruik vir keuringsdoeleindes is werkmonsters (work samples). Werkmonsters is ' $n$ benadering wat veel belofte inhou vir personeeltoetsing waaroor in Suid-Afrika relatief min navorsing gedoen is.

Die doel met hierdie artikel is om 'n oorsig van die navorsing met werkmonsters te gee. In 'n latere artikel in Perspektiewe in die Bedryfsielkunde word 'n empiriese valideringstudie van werkmonstertoetse in die mynbou-industrie gerapporteer.

Daar is beroepe waarvoor die keuring van personeel deur middel van werkmonsters geskied. So byvoorbeeld kan stemtoetse vir radio-omroepers as werkmonsters beskou word. Dieselfde geld vir oudisies vir televisie, film- of toneelrolle. Die onderliggende beginsel van sulke werkmonsters is dat mense hulle bekwaamheid moet demonstreer vir die werk waarvoor hulle aansoek doen. Dit kan aanvaar word dat indien toepaslike werkvereistes in die toetstaak nageboots word, werkmonsters die potensiaal het om as voorspellers vir latere werkverrigting aangewend te kan word. 'n Geldige werkmonster is 'n abstraksie van die werk eerder as ' $n$

\footnotetext{
* Versoeke vir afskrifte moet aan die skrywer gerig word.
} 
direkte transformasie daarvan (Guion, 1965) en is 'n bruikbare tegniek om persone wat reeds oor die basiese vaardighede beskik om 'n beroep te kan bemeester, te toets, eerder as diegene wat oor die potensiaal beskik om sekere vaardighede aan te leer (Guion, 1965; Orpen, 1976).

Dit is 'n vereiste dat 'n werkmonstertoets 'n verteenwoordigende monster of replika van die aktiwiteite behels wat in die beroep, waarvan die toets ' $n$ werkmonster is, beoefen word (Guion, 1965; Lopez, 1975; Orpen, 1976; Robertson and Kandola, 1982). Nadat 60 werkmonsters deur Asher en Sciarrino (1974) bestudeer is, het hulle dit in twee groepe geklassifiseer, naamlik motoriese en verbale werkmonsters. Motoriese werkmonsters behels die manipulasie van objekte soos masjinerie of toerusting, terwyl verbale werkmonsters probleemsituasies behels wat verbaalgeoriënteerd is, soos geskrewe teks- of verbale kommunikasie.

Werkmonsters kan suksesvol as voorspellers of as kriteria aangewend word (Guion, 1965; Dunnette, 1976). As voorspellers is werkmonsters onder andere aangewend vir die keuring van klerke. Voorbeelde van sulke werkmonsters is die SRA Typing Ability Test en die Bennett Stenographic Proficiency Tests om onderskeidelik tik- en snelskrifbekwaamheid te voorspel (Guion, 1965). Baie beroepsbekwaamheidtoetse is gestandaardiseerde werkmonsters (Anastasi, 1963).

As kriteria is werkmonsters veral aangewend wanneer ander objektiewe kriteria nie beskikbaar was nie, soos met die ontwikkeling van die General Aptitude Test Battery vir proeflesers en ander soortgelyke beroepe (Guion, 1965). Uit 'n oorsig van twaalf jaar se publikasies in Personnel Psychology se Validity Information Exchange het geblyk dat in 82 persent van alle valideringstudies gebruik gemaak is van direkte metings van die werk, soos werkmonsters of werklike werkverrigting, as kriteria (Dunnette, 1976).

\section{Aanwendingmetodes van werkmonstertoetse}

Daar bestaan twee moontlike metodes waarop werkmonsters aangewend kan word. Die eerste metode is die gewone toetssituasie, naamlik 'n eenmalige onderwerping van die toetslinge aan die toets, gevolg deur die waardebepaling en interpretasie.

Die tweede moontlikheid behels 'n leer-en-toetssituasie. Hierdie benadering met werkmonsters is deur Siegel en Bergman (1975) gevestig en die "miniature job training and evaluation approach" genoem. Die basiese aanname is dat 'n persoon wat die vermoë het om die werkmonstertaak aan te leer en dit daarna suksesvol kan uitvoer, in staat behoort te wees 
om die werk wat deur die werkmonster verteenwoordig word suksesvol te kan verrig na die toepaslike opleiding (Siegel en Bergman, 1975; Siegel, 1978). So word verseker dat alle persone 'n regverdige kans kry om aan te toon of hulle die werkmonstertaak - en moontlik die betrokke beroep - kan bemeester.

\section{Voordele}

Werkmonstertoetse het sekere voordele bo ander sielkundige toetse vir personeelkeuring. Die opvallendste voordeel van 'n geldige werkmonster is die ooreenkoms wat dit het met die werk waarvan dit 'n replika is. O'Leary $(1973 ; 1974)$ stel dit dat daar 'n direkte verband is tussen die taaksimulasie en die gedrag wat voorspel word. Om hierdie rede word daar dikwels hoë geldigheidkoëffisiënte behaal wanneer werkmonsters gebruik word om werkverrigting op spesifieke take te bepaal.

Vanweë die hoë inhoudsgeldigheid diskrimineer werkmonsters nie onregverdig tussen applikante vir die betrokke werk nie (Mount, Muchinsky en Hanser, 1977; O'Leary, 1973; Muchinsky, 1975; Taylor, 1982). In hierdie verband het Wernimont en Campbell (1968) gemeld dat persone wat lae tellings op keuringstoetse behaal gewoonlik afgekeur word sonder dat in ag geneem word dat sulke persone gedurende opleiding die toepaslike kennis en vaardighede wat nie deur die toets gemeet word nie, kan aanleer.

Dit behoort nie te gebeur met werkmonstertoetse wanneer persone die kans gegun is om die taak aan te leer nie. Indien 'n persoon onsuksesvol is met die aanleer van die werkmonstertaak, kan met groter sekerheid as in die geval van ander toetse voorspel word dat die persoon ook onsuksesvol sal wees om die betrokke beroep te bemeester.

Die billikheid van werkmonsters as keuringsinstrumente hoef nie in dieselfde mate as papier-en-potloodtoetse bevraagteken te word nie. Baie toetse gebruik "middelklas"-konsepte en is onregverdig wanneer dit toegepas word op persone wat nie "middelklas"-konsepte ken nie of wat 'n lae opvoedkundige peil het (Wernimont and Campbell, 1968). Verder is sommige toetse kultuurgebonde (O'Leary, 1973; Taylor, 1982). Daar is gevind (Schmidt, Greenthal, Hunter, Berner en Seaton, 1977) dat Swartmense in 'n ongunstiger posisie ten opsigte van 'n toets as die werk self is, en dat werkmonsters hierdie probleem oorkom, aangesien die enigste verskille tussen rasse, verskille ten opsigte van werkverrigting is. Daar is bevestig dat geldige werkmonsters nie sydig is ten opsigte van ras nie (Brugnoli, Campion en Basen, 1979). 
As gevolg van die hoë voorkomsgeldigheid behoort mense beter gemotiveerd te wees, en minder weerstand te openbaar om aan werkmonstertoetse as ander toetse waarvan die voorkomsgeldigheid laag is, onderwerp te word (Robertson en Mindel, 1980; Robertson en Kandola, 1982; Taylor, 1982). Hierdie feit is empiries bevestig deur middel van ondervraging van persone nadat hulle aan toetsing met werkmonsters onderwerp was (Siegel, 1978; Schmidt et al., 1977).

Vals response en responsstyl wat mag voorkom wanneer sielkundige toetse gedoen word, is tot 'n minimum beperk by werkmonstertoetse, aangesien die klem op gedragmonsters val en nie op persoonlike weergawe van idees, houdings en belangstellings nie (Wernimont en Campbell, 1968).

Die argument dat ' $n$ sielkundige toets in baie gevalle die privaatheid van die individu skend, is nie van toepassing op werkmonstertoetse nie; slegs nagebootste aspekte van die werk waarvoor die applikant getoets word, is ter sprake (Wernimont en Campbell, 1968).

Aangesien werkmonsters werkverrigting in opleidingprogramme suksesvol voorspel, het hierdie tipe toetse die voordeel dat dit die getal ongeskikte persone vir 'n opleidingskursus kan verminder (Taylor, 1982).

Terwyl 'n werkmonstertoets 'n organisasie help om die geskiktheid van 'n applikant vir 'n werk te bepaal, verskaf dit terselfdertyd die geleentheid aan die applikant om die geskiktheid van die moontlike toekomstige werk vir homself te bepaal (O' Leary, 1973; Robertson en Mindel, 1980).

Aangesien werkmonstertoetse praktiese toetse is, is dit geskik vir gebruik wanneer die toetslinge semi- tot ongeletterde persone is.

\section{Nadele}

Afgesien van bogenoemde voordele het werkmonstertoetse, net soos ander sielkundige toetse, sekere nadele. Die grootste nadeel van werkmonstertoetse is dat dit vir baie beroepe bykans onmoontlik sal wees om sulke toetse te standaardiseer. Die komplekse aard van baie beroepe sal dit moeilik maak om verteenwoordigende werkelemente in 'n werkmonster na te boots (O'Leary, 1973). Dit is veral die geval met beroepe wat heterogeen van aard is of abstrakte redeneervermoë vereis (Thomas, 1971). 
Taylor (1982) meld ook dat die meeste navorsing met werkmonsters gedoen is vir beroepe wat uitsluitlik psigomotoriese vaardighede vereis. 'n Swak punt van werkmonstertoetse is dat die geldigheid daarvan met verloop van tyd verswak wanneer latere werkverrigting as kriterium gebruik word, veral indien werkmetodes verander word soos wat werkervaring toeneem (Robertson en Kandola, 1982). Die tipe toetse is nie suksesvol met die voorspelling van werkverrigting op die langtermyn nie (Taylor, 1982).

Werkmonstertoetse het ook beperking as keuringinstrumente vir beroepe wat werk met mense behels. Die kennis, vaardighede en vermoëns wat nodig is kan nie betroubaar deur 'n werkmonster gemeet word nie, aangesien sukses in die werk 'n funksie is van die interaksie tussen mense (Muchinsky, 1975).

Aangesien werkmonstertoetse inhoudelik baie spesifiek is, kan dit aanleiding gee tot die opstel van 'n oormatige aantal toetse vir ' $n$ wye verskeidenheid van beroepe in teenstelling met konvensionele toetse wat breë onderliggende eienskappe meet (Taylor, 1982).

Aangesien werkmonstertoetse hoofsaaklik bekwaamheidtoetse is, kan dit slegs meet wat persone kan doen en nie wat hulle sal doen nie. Blood (1974) beweer dat werkverrigting meer behels as bloot die besit van sekere eienskappe; dit behels ook toepaslike gedragspatrone om hierdie vermoëns te benut. Hierdie argument is egter ook van toepassing wanneer ander sielkundige toetse vir keuring gebruik word.

Die argument is aangevoer (Blood, 1974; O'Leary, 1974) dat werkmonstertoetse sydige response tot gevolg kan hê omdat dit persone kan benadeel wat nie oor toepaslike ervaring beskik nie. Daar moet op gewys word dat in die geval van ander toetse persone ook nie noodwendig beskik oor ervaring ten opsigte van die monster van gedrag wat ter sprake is nie.

Daar is beweer (O'Leary, 1973) dat werkmonstertoetse baie duur is om te ontwikkel en te implementeer, waarskynlik vanweë die relatief lae verhouding toetslinge tot toetsers met gevolglike lang administrasieperiodes.

\section{RESULTATE}

Na aanleiding van 'n oorsig van navorsingsbevindinge het Dunnette en Borman (1979, p. 513) beweer dat "carefully devised work samples have almost yielded validities superior to those shown for tests" en "job samples measures merit increased attention". 
Talle valideringstudies, veral oorsee, het aangetoon dat werkmonstertoetse net so suksesvol in die keuringproses aangewend kan word as ander sielkundige toetse. $\mathrm{Na}$ aanleiding van 'n evaluasie van die 60 werkmonstertoetse (Asher en Sciarrino, 1974), het geblyk dat wanneer werkverrigting die kriterium was, motoriese werkmonsters die tweede hoogste geldigheidkoëffisiënte gehad het, na biografiese veranderlikes wat beter voorspellers was. Sommige verbale werkmonsters was ook onder die beste voorspellers vir werkverrigting. Verbale werkmonsters het opleidingsukses beter as werkverrigtingsukses voorspel en het ten opsigte van opleidingkriteria hoër geldigheidkoëffisiënte as motoriese werkmonsters gehad.

Die meeste resente navorsing in verband met werkmonsters is onderneem met beroepe waar psigomotoriese vaardighede vereis word en 'n aantal studies (Campion, 1972; Muchinsky, 1975; Siegel en Bergman, 1975; Latti, 1978; Siegel, 1983) het bevestig dat werkmonstertoetse geldige voorspellers vir hierdie beroepe is.

Daar is gevind dat werktuigkundiges $(\mathrm{N}=34)$ se prestasie op vier werkmonstertoetse, wat tipiese meganiese herstelwerk aan 'n motorenjin behels het, betekenisvol en positief $(\mathrm{r}=0,46)$ gekorreleer het met die kriterium; beoordeling van werkverrigting deur voormanwerktuigkundiges. Die geldigheidkoëffisiënte van drie ander toetse - Test of Mechanical Comprehension $(r=-0,21)$, Wonderlick Personnel Test $(r=-0,32)$ en Short Employment Tests $(\mathrm{r}=-0,04 ;-0,09$ en $-0,10)$ - was negatief en nie statisties betekenisvol nie (Campion, 1972). In 'n soortgelyke studie het Muchinsky (1975) gevind dat werktuigkundiges se prestasie op vier werkmonstertoetse, wat meganiese foutdiagnose en herstelwerk behels het, 'n effektiewe keuringtegniek was (geen syfers is egter verstrek nie).

Siegel en Bergman (1975) het met hulle leer-en-toets metode van werkmonsters gevind dat die werkverrigting van werktuigkundiges $(\mathrm{N}=54)$ in die Amerikaanse Vloot na nege maande diens meesal beter voorspel kon word met ses werkmonstertoetse $(r=0,22$ tot 0,46$)$ as met toetse $(r=0,14$ tot 0,47$)$ wat op daardie stadium vir keuring gebruik was. Die werkmonstertoetse het bestaan uit identifikasie van gereedskap, onderhoud en meterlesing, foutopsporing en herstelwerk, beheer van toerusting en 'n monteringtaak. Dieselfde werkmonsters is as kriteria aangewend. In 'n tweede opvolgstudie na 18 maande diens is die teenoorgestelde resultate behaal $(r=0,15$ tot 0,30 vir werkmonsters; $r=0,05$ tot 0,50 vir toetse, $\mathrm{N}=34$ ). Hierdie studie is later op metodologiese gronde gekritiseer deur Cohen en Penner (1976) wat beweer het dat die superioriteit van werkmonsters nie voldoende bewys is nie aangesien nie alle voorspellers gebruik was om die meervoudige korrelasie te bereken nie. 
Siegel (1983) het na aanleiding van Cohen en Penner (1976) se kommentaar 'n tweede studie geloods met 'n groter steekproef $(\mathrm{N}=1034)$ wat bestaan het uit see-, brandweer- en lugkadette. Nege toepaslike werkmonsters is aangewend met Siegel en Bergman (1975) se leer-en-toets prosedure. Die kriterium was 'n beoordelingskaal wat twee keer voltooi was - na nege en na agtien maande werkervaring. Die korrelasies tussen die werkmonsters en kriterium was 0,37 en 0,30 na nege en agtien maande onderskeidelik vir die seekadette, 0,34 en 0,42 vir die brandweerkadette en 0,04 en 0,31 vir die lugkadette. Hierdie korrelasies was betekenisvol hoër as dié van die Armed Services Vocational Aptitude Battery en die kriterium. Die bevindinge bevestig dus die Siegel en Bergman (1975) ondersoek wat betref die sukses van die "miniature job training and evaluation" benadering tot keuring.

Slegs een plaaslike studie met betrekking tot werkmonstertoetse wat deur die Nasionale Instituut vir Personeelnavorsing onderneem is, het onder die aandag gekom. ' $n$ Toets, bekend as die Kurwestiktoets, is vir die keuring van Swart en Kleurling naaimasjienoperatrises in die klere-industrie gevalideer. Met twee beoordelingskale as kriteria, is geldigheidkoëffisiënte van 0,54 en 0,63 vir 42 Swart operatrises behaal. 'n Geldigheidkoëffisiënt van 0,48 is vir 103 Kleurling operatrises met dieselfde tipe kriterium behaal (Latti, 1978).

Werkmonstertoetse is ook vir ander beroepe, naamlik Vredesmagte (Gordon, 1967) en die Polisie (Gordon en Kleiman, 1976) aangewend.

Daar is geen verskil gevind tussen die voorspellinggeldigheid van kliniese beoordeling $(r=0,39)$, ' $n$ psigometriese instrument $(r=0,37)$ en 'n werkmonster $(r=0,41)$ vir Vredesmagte ( $\mathrm{N}=172)$ met 'n opleidingsukseskriterium nie (Gordon, 1967). Hoewel werkmonsters sukses in opleiding kon voorspel, was dit nie betekenisvol beter as die ander metodes nie.

In 'n studie met vier groepe Polisiebeamptes $(\mathrm{N}=29,27,45,56$ onderskeidelik) is gevind dat motoriese en verbale werkmonsters, wat opleidingaktiwiteite behels het, beter voorspellers ( $\mathrm{r}=0,52 ; 0,72 ; 0,64 ; 0,51)$ as die Otis-Lennon Mental Ability Test $(\mathrm{r}=0,33$; $0,15 ; 0,56 ; 0,21)$ was met sukses in opleiding as kriterium (Gordon en Kleiman, 1976).

Opleibaarheidstoetse (trainability tests), wat 'n spesiale vorm van werkmonstertoetse is, is reeds vir 'n aantal beroepe wat psigomotoriese vaardighede vereis, gevalideer (Robertson en Downs, 1979; Robertson en Mindel, 1980). 
Die navorsing wat hier aangehaal is, dui daarop dat werkmonsters 'n suksesvolle tegniek is wat aangewend kan word in personeeltoetsing, veral wanneer die beroepe waarvoor gekeur word, psigomotoriese vaardighede vereis. Hierdie bevindinge het dan ook gedien as motivering vir 'n valideringstudie ten opsigte van Swart ambagsmanhelpers in die mynbouindustrie, wat in 'n aparte opvolgartikel gerapporteer word.

\section{OPSOMMING}

' $n$ Werkmonster is 'n replika van die werk waarmee applikante demonstreer dat hulle oor die nodige vaardighede beskik om die werkmonster en gevolglik die beroep wat dit verteenwoordig, suksesvol kan verrig. Die grootste voordeel van werkmonsters is die ooreenkoms daarvan met die werk waarvan dit 'n replika is en dus onregverdige diskriminasie tussen applikante verhoed. Die grootste nadeel van werkmonsters is dat vir baie beroepe dit onmoontlik sal wees om sulke toetse te standaardiseer. ' $n$ Literatuurstudie het aangetoon dat werkmonsters betroubare en geldige keuringtoetse is, veral vir beroepe wat psigomotoriese vaardighede vereis.

\section{VERWYSINGS}

Anastasi, A. Psychological testing (2nd Ed.) New York: Macmillan, 1963.

Asher, J.J. en Sciarrino, J.A. Realistic work sample tests: a review. Personnel Psychology. $1974,27,519-533$

Blood, M.R. Job samples: a better approach to selection testing? American Psychologist. 1974, 29, 218-219.

Brugnoli, G.A.; Campion, J.E. en Basen, J.A. Racial bias in the use of work samples for personnel selection. Journal of Applied Psychology. 1979, 64, 119-123.

Campion, J.E. Work sampling for personnel selection. Journal of Applied Psychology. 1972, 56, 40-44.

Cohen, S.L. en Penner, L.A. The rigors of predictive validation: some comments on "a job learning approach to performance prediction". Personnel Psychology. 1976, 29, 595600.

Dunnette, M.D. Aptitudes, abilities and skills. In: M.D. Dunnette (Ed.) Handbook of

Industrial and Organizational Psychology (pp. 473-520). Chicago: Rand McNally, 1976.

Dunnette, M.D. en Borman, W.C. Personnel selection and classification systems. Annual Review of Psychology, 1979, 30, 477-525.

Gordon, L.V. Clinical, psychometric and work-sample approaches in the prediction of success in Peace Corps training. Journal of Applied Psychology, 1967, 51, 111-119.

Gordon, M.E. en Kleiman, L.S. The prediction of trainability using a work sample test and an aptitude test: a direct comparison. Personnel Psychology, 1976, 29, 243-253.

Guion, R.M. Personnel testing. New York: McGraw-Hill, 1965. 
Lätti, V.I. 'n Keuringsbattery vir Swart en Kleurling naaimasjienoperatrises. Perspektiewe in die Bedryfsielkunde, 1978, 4.5, 1-19.

Lopez, F.M. Personnel interviewing - Theory and practice (2nd Ed.) New York: McGrawHill, 1975.

Mount, M.K.; Muchinsky, P.M. en Hanser, L.M. The predictive validity of a work sample: a laboratory study. Personnel Psychology, 1977, 30, 637-645.

Muchinsky, P.M. Utility of work samples. Personnel Journal, 1975, 54, 218-220.

O'Leary, L.R. Fair employment, sound psychometric practice and reality. American Psychologist, 1973, 28, 147-150.

O'Leary, L.R. O'Leary replies. American Psychologist, 1974, 29, 217-218.

Orpen, C. Productivity and Black workers in South Africa. Johannesburg: Juta, 1976.

Robertson, I.T. en Downs, S. Learning and the prediction of performance development of trainability testing in the United Kingdom. Journal of Applied Psychology, 1979, 64, 42-50.

Robertson, I.T. en Kandola, R.S. Work sample tests: Validity, adverse impact and application reaction. Journal of Occupational Psychology, 1982, 55(3), 171-183.

Robertson, I.T. en Mindel, R.M. A study of trainability testing. Journal of Occupational Psychology, 1980, 53, 131-138.

Schmidt, F.L.; Greenthal, A.L.; Hunter, J.E.; Berner, J.G. en Seaton, Felecia W. Job Sample vs. paper and pencil trades and technical tests: adverse impact and examinee attitudes. Personnel Psychology, 1977, 30, 187-197.

Siegel, A.I. Miniature job training and evaluation as a selection/classification device. Human Factors, 1978, 20, 189-199.

Siegel, A.I. The miniature job training and evaluation approach: Additional findings. Personnel Psychology, 1983, 36(1), 41-56.

Siegel, A.I. en Bergman, B.A. A job learning approach to performance prediction. Personnel Psychology, 1975, 28, 325-339.

Taylor, T.R. Trainability testing: Pros and cons. South African Journal of Psychology, 1982, 12, 51-56.

Thomas, K.R. The omnipotence of work samples: a closer look. Vocational Evaluation and Work Adjustment Bulletin, 1971, 4, 10-12.

Wernimont, P.F. en Campbell, J. P. Signs, samples, and criteria. Journal of Applied Psychology, 1968, 52, 372-376. 
